\title{
Tsunamis from submarine landslides
}

\author{
David R Tappin ${ }^{1}$ \\ ${ }^{1}$ British Geological Survey, Keyworth, Nottingham, NG12 5GG \\ Correspondence to: Prof. David Tappin, British Geological Survey, Keyworth, Nottingham, NG12 5GG \\ Tel: +44 1159363449 \\ Email: drta@bgs.ac.uk
}

\section{'Tsunamis from submarine landslides'}

\author{
David R Tappin
}

British Geological Survey, Keyworth, Nottingham, NG12 5GG

\begin{abstract}
Most tsunamis are generated by earthquakes, with secondary, less frequent, mechanisms including subaerial and submarine landslides, volcanic eruptions and (extra-terrestrial) bolide impacts. Different mechanisms generate tsunamis with different magnitudes, travel distances and impacts. Submarine landslides had been mapped and studied for decades but records suggested that only a few had generated tsunamis, and that these were minor. It was not until 1998, when a slump on the seabed offshore of northern Papua New Guinea caused a tsunami wave up to $15 \mathrm{~m}$ high that killed over 2,200 people, was the significance of submarine landslides in tsunami generation realised. A combination of new (multibeam) seabed mapping technology and the development of improved numerical tsunami models for tsunami generation led to the recognition of the landslide tsunami mechanism of the PNG event. As a result the hazard from submarine landslides in tsunami generation is now recognised and better understood. Extensive mapping of ocean margins reveals that submarine landslides are common. Although many of these probably generated tsunamis, few have been identified, so their hazard remains uncertain. This article describes how the hazard from submarine landslide tsunamis was first recognised, how submarine landslides generate tsunamis, why they were previously discounted as a major hazard, and their potential hazards. An important aspect of the recognition of the tsunami hazard from submarine landslides has been the significance of geology, which has contributed to a subject previously dominated by seismologists.
\end{abstract}

\section{Tsunami mechanisms}

Over recent decades the significant number of destructive, if not catastrophic, tsunamis seems to suggest that we are living in an unusual period when there is an increased frequency of these events - 'The Age of Tsunamis'? Although this is unlikely when considered over longer timescales, there is now a greater awareness of the hazard from tsunamis and, in association with improved technology in researching them, better understanding of their mechanisms and impacts. One of the major aspects contributing to improved understanding of natural hazards, often overlooked and especially with geohazards where major events are rare and taking place over long, geological timescales, is that significant advances in understanding are made only when something catastrophic happens.

For earthquake mechanisms, one of the most recent seminal events was in the Indian Ocean in 2004. This was in an unexpected location. The earthquake magnitude was much larger than expected. The associated tsunami had disastrous consequences. Over 220,000 people drowned and, because there was no warning system, over 100,000 of these perished in locations where evacuation could (and should) have taken place. Belatedly, now in the region, a tsunami warning system has been established.

A lesser known tsunami, but as seminal as that in the Indian Ocean, struck the north coast of Papua New Guinea (PNG) on July $17^{\text {th }} 1998$ (Figure 1). Here, after a relatively small earthquake, an extremely focussed tsunami up to $15 \mathrm{~m}$ high flooded a $40 \mathrm{~km}$ section of the local coast. 2,200 people were drowned. The earthquake magnitude $(M w 7.0)$ compared to the elevation and impact of the tsunami, raised fundamental questions about the tsunami mechanism. Although at the time some scientists argued for an earthquake mechanism for the local tsunami, it was generally agreed that the earthquake magnitude was too small to generate the recorded tsunami elevations. It was not a 'tsunami' earthquake, where the tsunami is much greater than expected from the source magnitude. Thus the most likely alternative tsunami mechanism was a submarine landslide. 


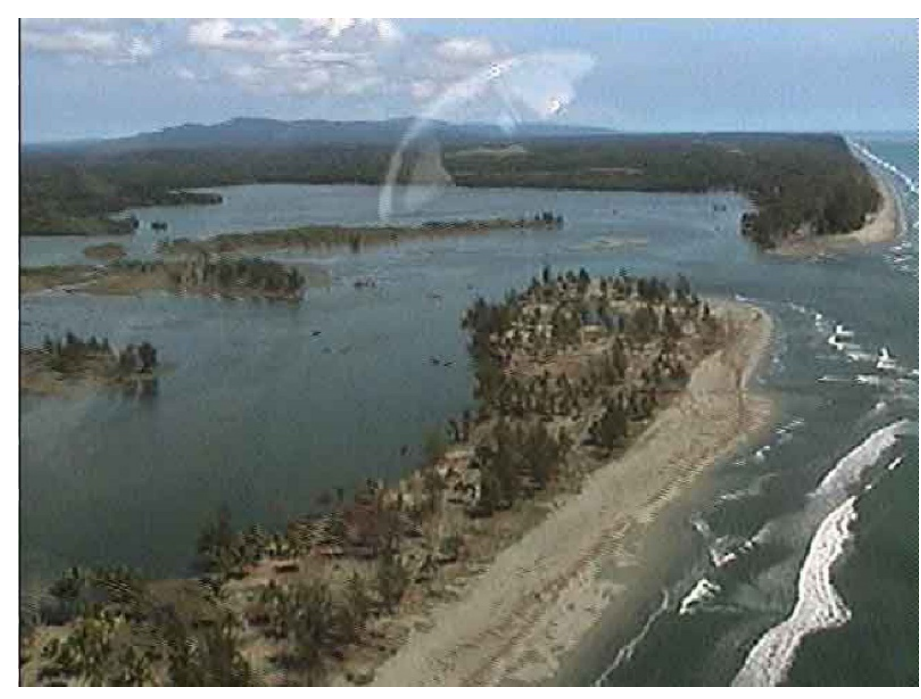

Figure 1 Aerial photograph of the Sissano lagoon that was devastated by the PNG tsunami of July 1998 (Image courtesy of the University of Southern California tsunami website).

\section{High impact grabs the attention}

The impact of these major disasters - the Indian Ocean and PNG - is obviously from the massive death toll. However, the subsequent response to these events is often one of surprise that, because of modern understanding and technologies, so many people die. In the instance of the Indian Ocean, there was no warning given that might have reduced the death toll in the far field. The tsunami also killed so many people. The great majority were local inhabitants but, unusually, many people who died were from outside the region, visiting as tourists. These type of disasters - volcanic eruptions, earthquakes, tsunamis - usually happen to 'other people', often in the third world. The Indian Ocean event was thus unusual in that it really made people living in 'safe' geological regions outside of the region aware of the dangers to people who live in these 'idyllic' locations all of the time.

\section{The 'wake-up' call - PNG}

With regard to PNG, to determine whether a submarine landslide generated the tsunami required sophisticated, marine hydroacoustic data, such as bathymetry and sub-seabed seismic (Figure 2), but none of these data were available to give any indication of the seabed morphology. Yet, after two rapidly organised marine surveys six months after the

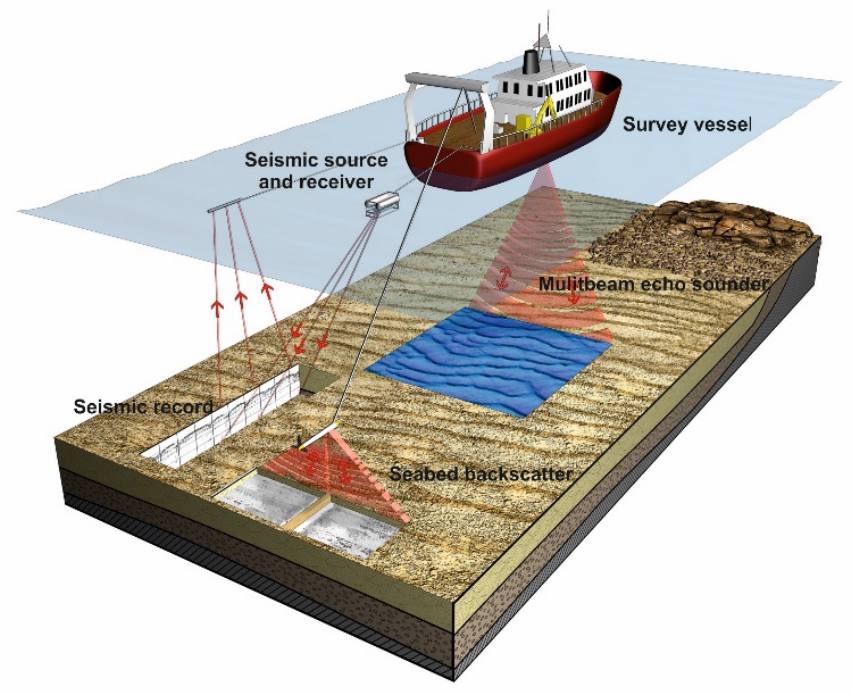

Figure 2 Marine geophysical mapping techniques. Using multibeam echosounder, backscatter and seismic technology the seabed and subseabed structure can be mapped to a high resolution that allows features such as landslides to be identified (From James et al, 2011. The MALSF synthesis study in the central and eastern English Channel. British Geological Survey Open Report OR/11/01).

event, evidence of a submarine landslide was indeed found offshore of the devastated area. Numerical tsunami models based on this landslide supported this as the most likely tsunami mechanism, although it took a number of years for this to become generally accepted. The PNG marine surveys in 1999 were the first to be organised in direct response to a catastrophic tsunami. From the comprehensive hydroacoustic data set of multibeam bathymetry and seismic the landslide was located, and its' mechanism - a slump identified. The marine data for the first time formed the basis for the numerical tsunami models that showed the landslide to have generated the onland tsunami elevations.

With hindsight, the events following on from the tsunami - the marine surveys, the numerical modelling and the recognition of the submarine landslide mechanism - seem now to be unexceptionable. In 1999, however, they were ground breaking, because the tsunami hazard from submarine landslide mechanisms was unrecognised. Here we review why before 1998 submarine landslides were not recognised as dangerous tsunami-generation mechanisms and why the subsequent research, which formed the basis for the improved understanding of submarine landslide tsunami, was a direct consequence of the PNG event. We frame the discussion on submarine landslide tsunamis around PNG because it was such a major, benchmark, study. Not only did PNG result in major advances in understanding tsunami hazard from submarine landslides, which were analogous to those from earthquakes resulting from the 2004 Indian Ocean event, but it also established new methodologies for investigating these events.

\section{Why landslides were overlooked as hazardous tsunami mechanisms}

Reading today the published literature on submarine landslides and tsunamis available prior to 1998 , it is not readily apparent why their hazard was overlooked in 1998/9. Submarine landslides, including slumps, debris flows and turbidites, had been recognised as potential tsunami mechanisms since the $19^{\text {th }}$ century and scientifically researched for decades. There had been a number of destructive historical events. These 
included those of 1929 on the Grand Banks, 1946 in the Aleutians, 1964 in Alaska, 1975 at Kitimat, Canada and 1992 at Flores Island in Indonesia (Figure 3). Early work on the Storegga landslide published in 1982 demonstrated that a significant tsunami up to 10-20 metres in elevation was generated. From some historical events' there was a heavy death toll, for example at Flores over 1,000 people died in the tsunami. With others, there was uncertainty over the landslide contribution to the tsunami. Only those tsunamis in 1964 (Alaska) and 1975 (Kitimat, Alaska) were

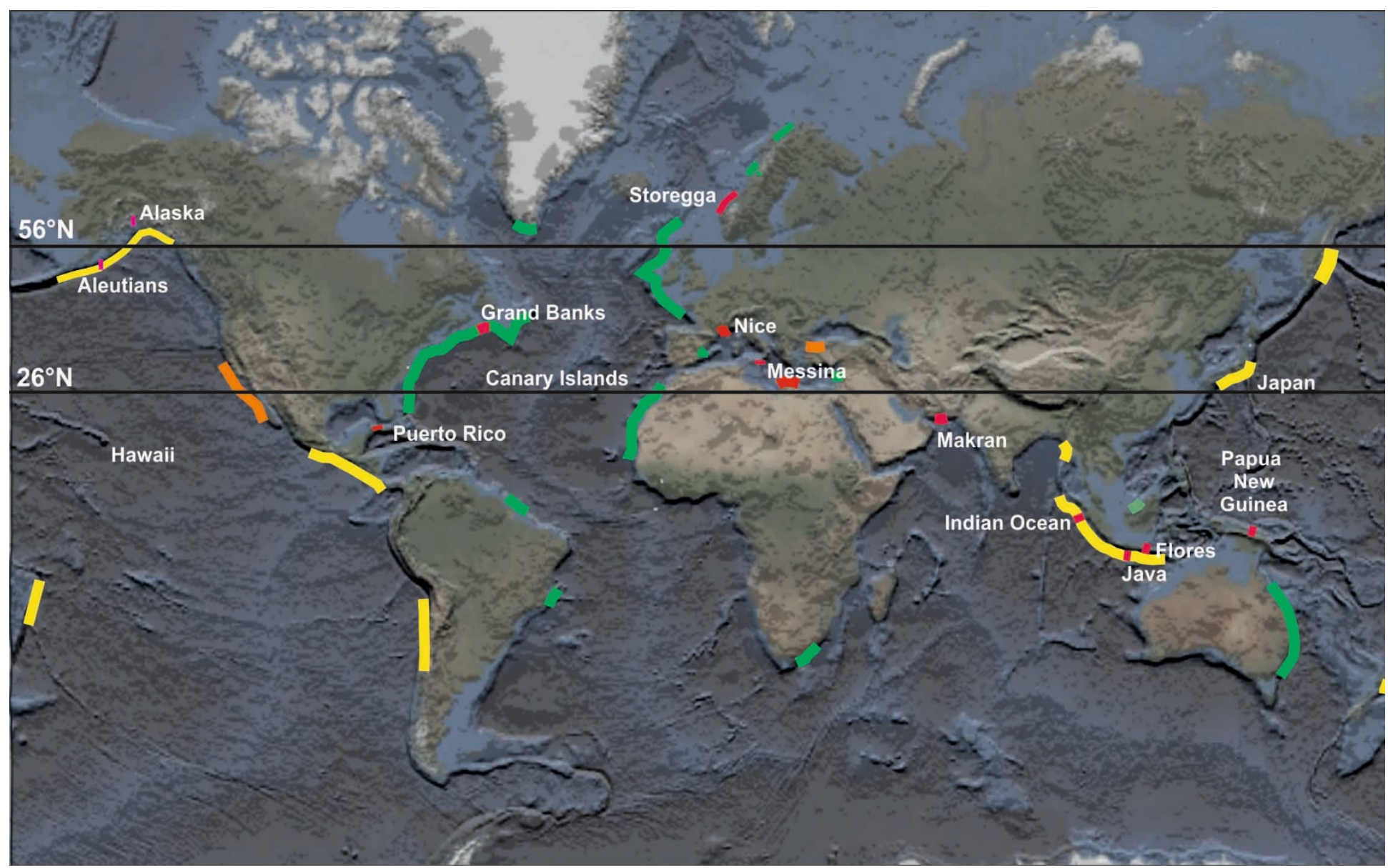

Figure 3 Global distribution of mapped submarine landslides (SLs). Green lines: SLs on passive margins. Yellow lines: SLs located along convergent margins. Orange lines: SLs along strike-slip margins. Red lines: locations of SL generated tsunamis, or where there may be a SL contribution. Black latitudinal lines mark the boundaries of glacial and non-glacial SL influence.

definitely associated with submarine landslides. With some events, the tsunami mechanisms were uncertain or disputed, but mainly attributed to earthquakes, although there were suspicions that there may have been an additional - landslide - mechanism.

Even with the Grand Banks tsunami, which was undoubtedly landslide-generated, for many years this was 'assumed', rather than proven. A major problem in determining submarine landslide mechanisms until the 1980's was the lack of a marine technology to map in high resolution seabed morphology. Before this, geological investigation of landslide events was mainly from seabed sampling or 2-D seismic technologies. These however, could not map the seabed in the high resolution available today using multibeam bathymetry, or image the underlying sedimentary structure with seismic (Figure 2) in sufficient resolution to fully understand the different morphologies and mechanisms of landslide failure.

Apart from deficiencies in seabed mapping, numerical models of submarine landslide tsunami in 1998 were mainly theoretical and experimental. They mostly assumed a deforming landslide or mudflow, which only produced small and local tsunamis. There had been only one numerical model of a submarine landslide tsunami, published in 1992, based on the prehistorical Storegga event off the coast of Norway. This was the only attempt to simulate a submarine landslide tsunami, validated by runups identified from sediments laid down as the tsunami flooded the coast. Similar sedimentary evidence in the Hawaiian Islands, had led to the identification in the 1980's of 'megatsunamis', 100's of metres in elevation, resulting from the massive prehistorical collapses of the volcanoes here. There was controversy over the tsunamis, however, because of alternative theories on the sediments' origins and by theoretical numerical models.

We now recognise that submarine landslides generate tsunamis in a manner analogous to earthquakes; by a vertical displacement of the seabed that creates a similar displacement at the sea surface (Figure 4). The major difference is that earthquakes rupture at three to four kilometres a second, which makes the input of energy into the water column almost instantaneous compared to the long-wave phase velocity of the ocean that governs tsunami generation. By contrast, submarine landslides travel at $10 \mathrm{~s}$ to $100 \mathrm{~s}$ of metres a second. The longer source times of landslides reduces their efficiency in tsunami generation. The horizontal areas of seabed disturbance from submarine landslides are also much smaller than those from earthquakes, and the resulting tsunamis strongly directional. Another major problem with most numerical models was that they did not address the vertical fluid accelerations generated by landslides located where water depths
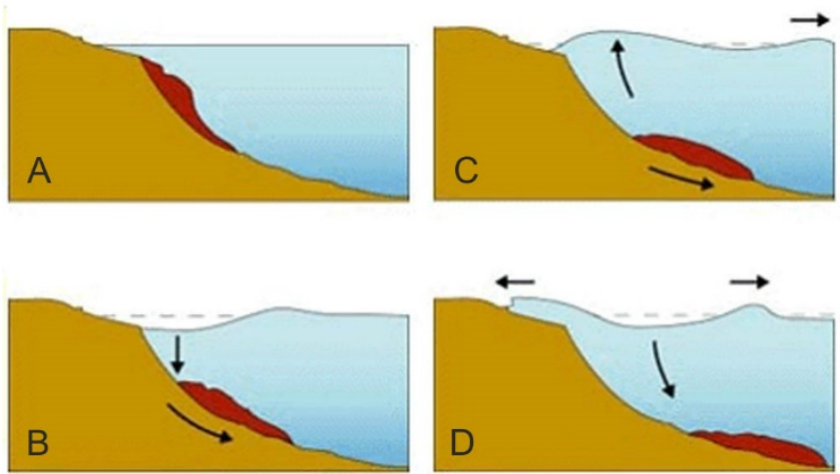

Figure 4 How submarine landslides generate tsunamis. (a) Prefailure, (b) initial slip and surface drag down above the rear of the SMF, (c) positive and negative wave generation, and (d) continued wave propagation. 
changed rapidly, and where waves break nearshore. All-in-all, these factors led to a general assumption that submarine landslides were much less efficient in tsunami generation, except in certain circumstances, such as in enclosed water such as fjords.

It is apparent therefore that in 1998, in the absence of a major event, tsunami generation from submarine landslides was not considered a major hazard. The physics of tsunami generation were considered unlikely to generate elevated waves. Numerical models were theoretical. Only translational submarine landslides, mainly in fjords and from theoretical modelling, were considered in tsunami generation, and only one prehistoric event had been modelled and validated from sedimentary evidence. From these perspectives it is now apparent that there were major misunderstandings that could be attributed to a disconnect between numerical tsunami modellers and marine geologists who studied submarine landslides. The research on tsunami impact from sediments laid down when the land was flooded, which was available since the mid 1980 's, was also not considered. All this was to significantly change when the devastating PNG tsunami struck.

\section{The Papua New Guinea tsunami - 1998}

After the tsunami struck, the news reports from PNG first indicated a major event as evidenced from the significant loss of life and massive coastal destruction; findings soon confirmed by the observations of the responsive science, field survey team that visited the area a few weeks later. The PNG death toll of 2,200 people was surpassed only by the devastating tsunami that in 1933 struck the Sanriku coast of Japan. Comparison of the tsunami elevations in the context of the earthquake location, magnitude and timing, revealed major disconnects. The earthquake was too small and the tsunami struck 18 minutes afterwards, which was anomalous considering that the epicentre was so close to shore (Figure. 5). The major loss of life, together with the uncertainty over the tsunami mechanism led Alf Simpson, the Director of the South Pacific Geoscience Commission (SOPAC) based in Fiji, to make a plea for help in finding out what had happened. SOPAC is a regional intergovernmental organisation with the role of facilitating deep ocean research in the western Pacific Ocean. Alf requested countries involved in this research to provide a deep ocean research vessel to investigate the offshore area to determine whether a submarine landslide was present that could have generated the tsunami. France, Germany and the USA all tried to help, but could not because their research vessels were working outside of the region at that time - so the Japanese stepped in.

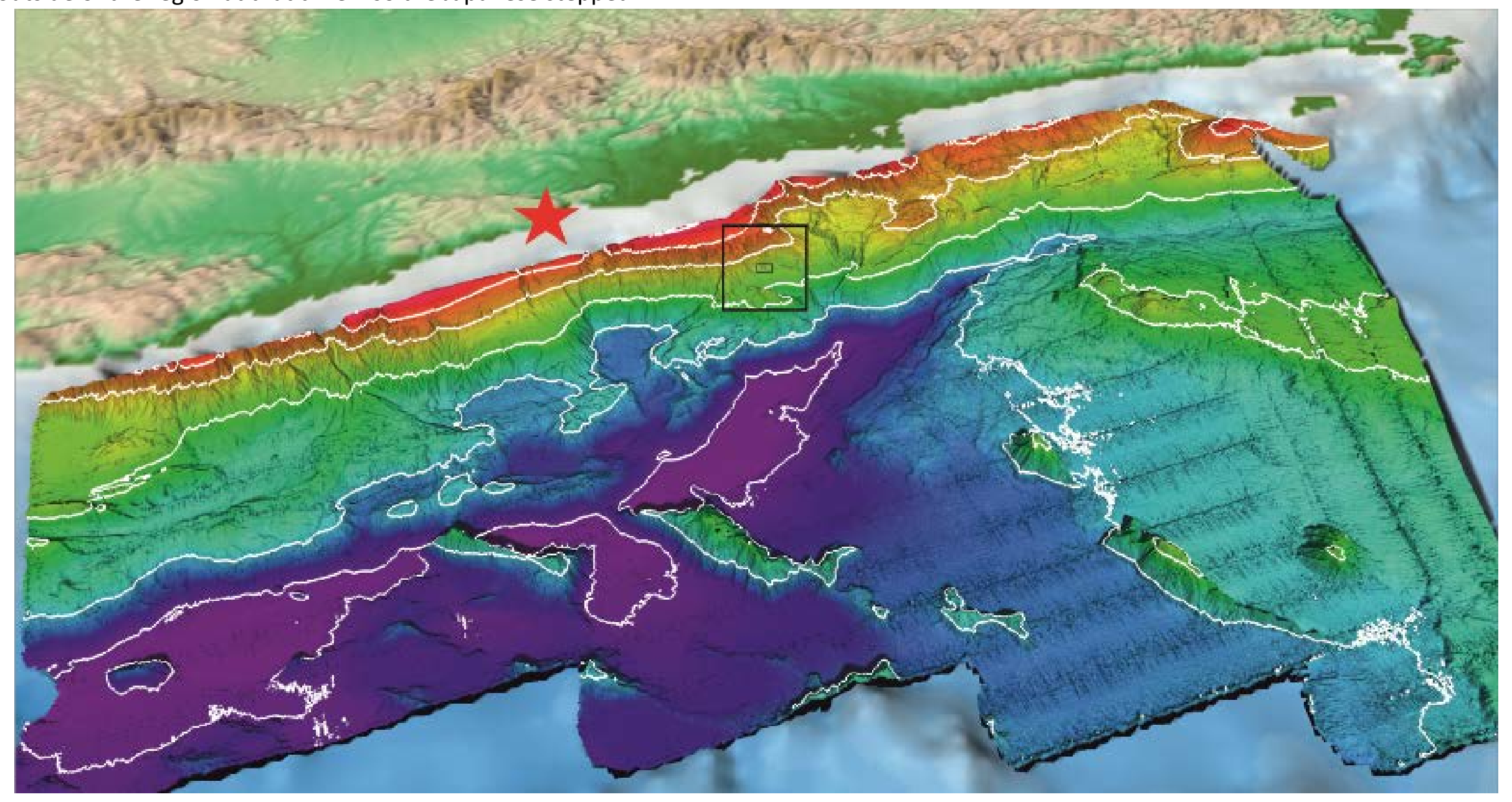

Figure 5 Digital elevation model of sea-floor relief with bathymetric contours offshore of northern Papua New Guinea looking south (vertical exaggeration $\mathrm{x4}$ ). The box shows the slump location in Figure 4. The red star is the associated earthquake. (Reproduced from Tappin, 2010).

The first two surveys took place in early 1999 with an international science team of marine geologists, seismologists and tsunami modellers. From offshore of northern PNG 19,000 km² of multibeam bathymetry and seismic data were acquired during 10 days of survey (Figures 5 and 6). In the region of the landslide, piston cores sampled the seabed sediment. Still and video photography imaged the seabed morphology and biotas (Figure 7). The multibeam echo sounder (MBES) technology used for the first time in the PNG surveys was developed during the 1960's by the USA for military use in aiding submarine navigation. The first operational non-military system was installed on the French research vessel, the Jean Charcot, in 1977. By 1990, more than 40 MBES systems were in operation for scientific use, mainly seamounts, fracture zones and sediment waves. MBES led to a revolution in marine science because large areas of the seabed could be mapped rapidly at high resolution in swath widths 10's of kilometres wide. From the data, digital elevation models (DEMs) were produced (Figure 5), which were in many ways similar to topographic maps onland. From the seabed morphology, the convergent margin was visualised, and an amphitheatre shaped feature, immediately offshore the devastated area, identified as formed from a rotational slump (Figure 6). Photographs and video imagery of the seabed revealed recent movement within the amphitheatre from fissures and cracks in sediment and limestones, and an associated proliferation of chemosynthetic faunas such as mussels and tube worms (Figure 7). These data confirmed this area as the most likely location for a slump generated tsunami. 


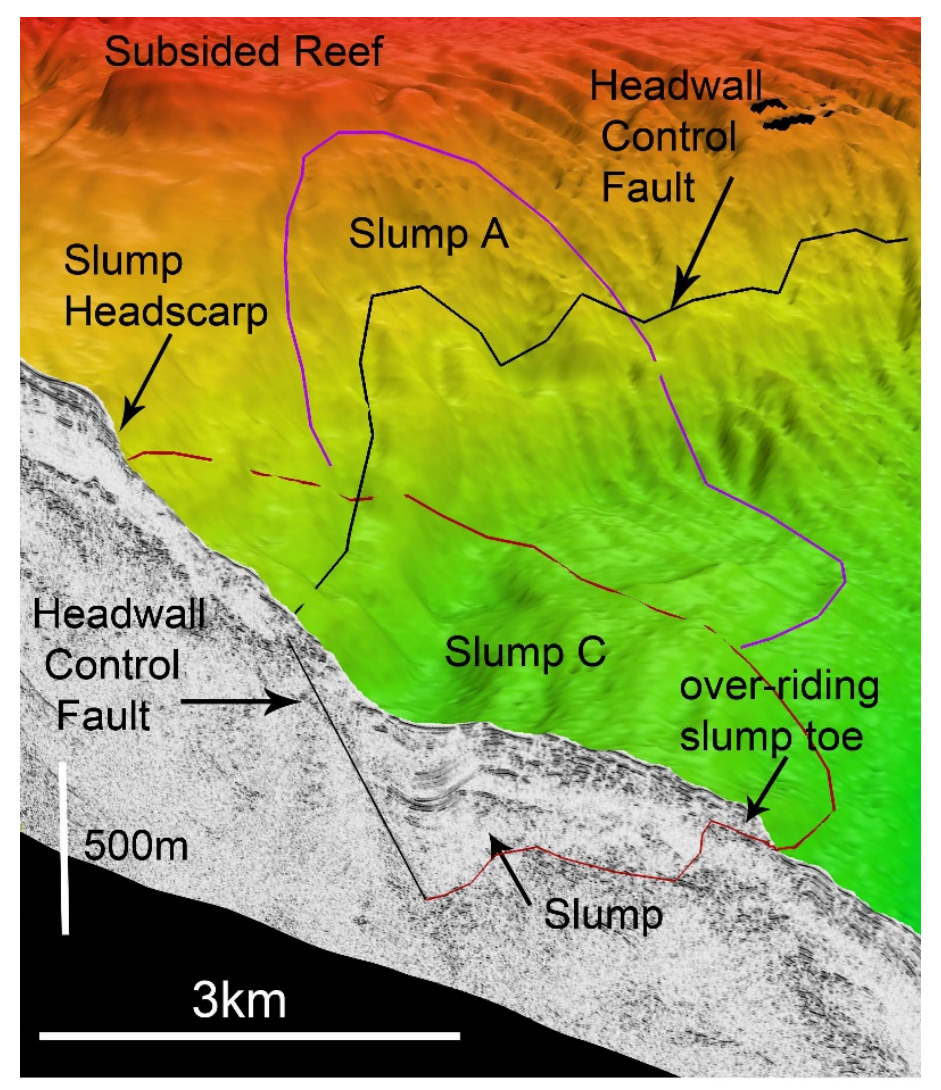

Figure 6 3-D cutaway section of the Papua New Guinea slump showing seabed bathymetry and sub-seabed seismic viewed from the northeast. (Vertical exaggeration x3). (Reproduced from Tappin, Watts, and Grilli (2008).

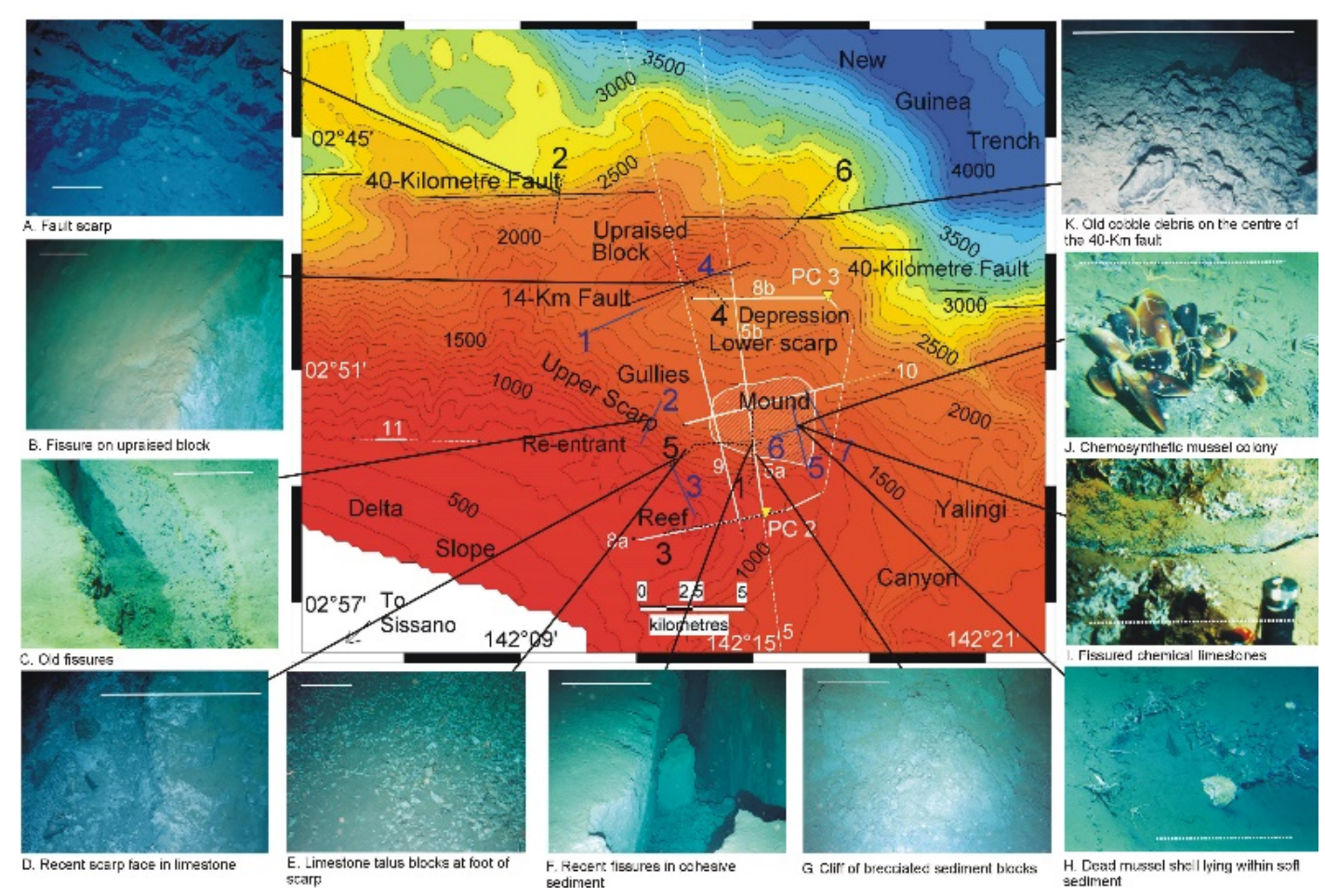

Figure 7 Digital elevation model of sea-floor relief with bathymetric contours offshore of northern Papua New Guinea looking south (vertical exaggeration $\mathrm{x} 4$ ). The box shows the slump location in Figure 4 . The red star is the associated earthquake. (Reproduced from Tappin, 200)

In January 1999, at the time of the first PNG survey, the available (mainly theoretical) numerical models of landslide tsunami were only applicable to deformable landslides, and inappropriate for modelling a seabed slump. So the first numerical simulation of a tsunami from the slump was devised at sea during data acquisition. It was rudimentary, with many assumptions not validated. Initial tsunami generation estimates were computed by hand, based on published (or soon to be published) literature. The model was an approximation based on a solid block 2-D underwater landslide sliding down a slope (Figure 4). This generated a maximum wave height of $6 \mathrm{~m}$ offshore of the sand spit (Figure 1), at the $10 \mathrm{~m}$ water depth contour. The model did not fully approximate the tsunami elevation and runup height distribution along the coast recorded by the onland surveys, but it was a major success because it reproduced the tsunami more accurately than from the associated earthquake which, based on a shallow-dipping rupture, generated a maximum wave height at the shore of $2 \mathrm{~m}$.

The numerical simulation of the sliding-block landslide model was a breakthrough because, for the first time, it computed the vertical water accelerations in tsunamis generated by submarine landslides. The results showed that for landslide tsunamis the mechanism of failure translational, sliding block, slump - is critical in simulating realistic events. The simulation also accounted for the differences in travel (propagation) between tsunamis from earthquakes and landslides. Tsunamis from landslides have higher frequencies and shorter wavelengths, thus their energy dissipates more rapidly (they are more dispersive) than earthquake-generated tsunamis, and thus do not travel as far. Once all the marine data from the first two surveys, (and three subsequent ones) were synthesised, significant improvements in tsunami generation resulted in further numerical models until the tsunami from the slump reasonably matched the onland observations (Figure 8). 


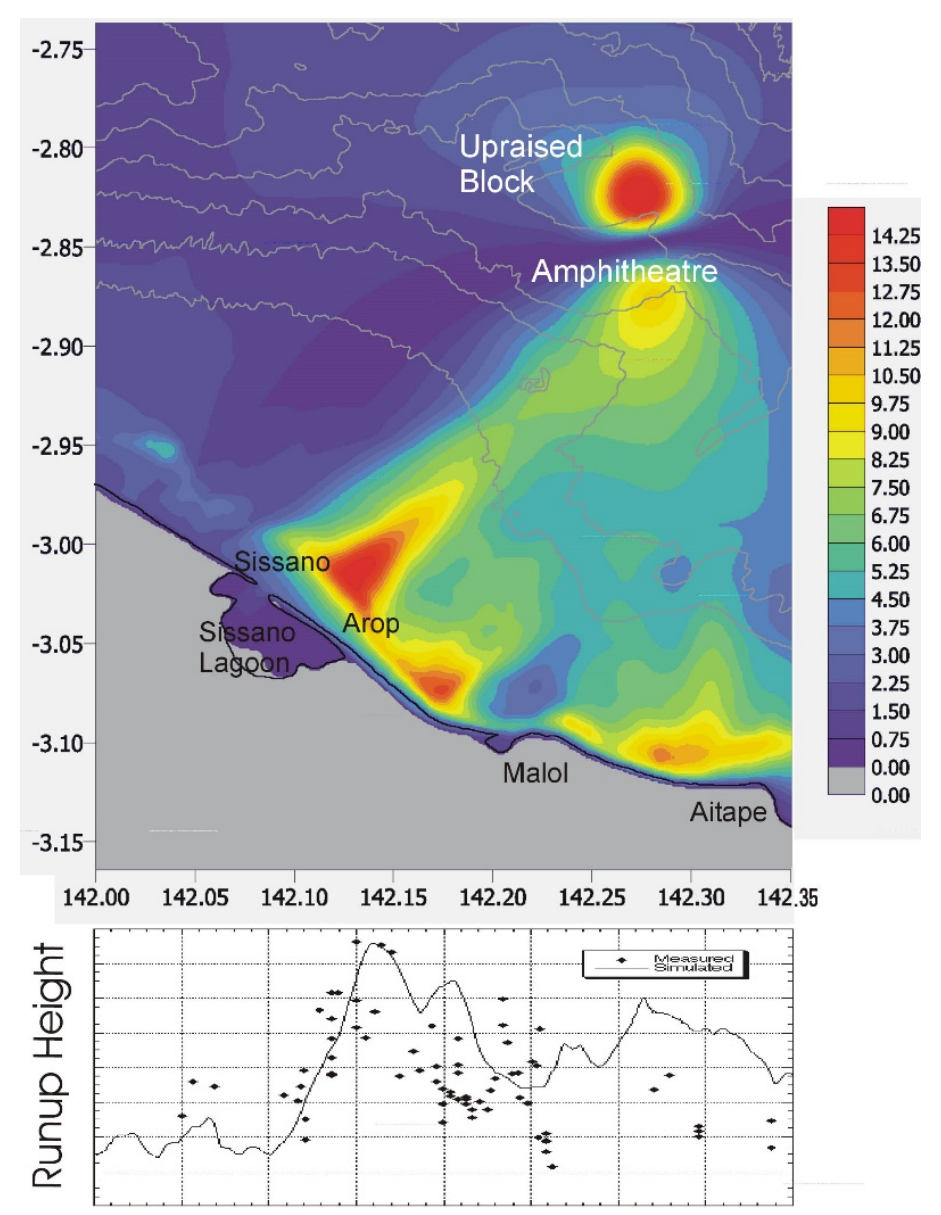

Figure 8 Papua New Guinea tsunami; upper; time-lapse image of the maximum wave elevation in metres. Depth contours are in $500 \mathrm{~m}$ intervals. Lower. Simulated wave maxima (line) agree well with maximum water elevations (diamonds) measured onshore. (Reproduced from Tappin et al., 2001).

\section{The ramifications from Papua New Guinea - raised awareness}

The identification of the submarine landslide mechanism for the PNG tsunami was a catalyst for the burst of research on the generation of tsunamis from submarine landslides. Some countries such as the USA began mapping their coastal margins to identify and evaluate the potential hazard. Where there was evidence that submarine landslides may have generated older tsunamis, these were re-evaluated. Many events, although suspected, remained unproven, usually because of the lack of seabed morphology. Deficiencies in existing numerical models began to be addressed and new models formulated, some based on real events and validated by real data. The importance of the different mechanisms of submarine landslide failure in tsunami generation was realised, and focussed studies on these carried out. Seabed mapping of the ocean margins showed how common submarine landslides are in these regions (Figure 3). So, since 1999 understanding of submarine landslide tsunami mechanisms and their hazard has advanced significantly. From the global mapping database, we now recognise how common submarine landslides are in most tectonic environments - along both passive, convergent and strike-slip margins. We now recognise that landslide failure along passive margins is complex but controlled by changes in climate (Figure 3). The controls on landslide failure along convergent margins are mainly tectonic.

\section{Passive margins}

Submarine landslides are now mapped along many passive margins, although few are associated with identified tsunamis (Figure 3). This may seem surprising, until it is realised that the identification of tsunamis, especially prehistoric events, is mainly from sediments deposited as the tsunamis flood the land. The preservation potential of these sediments is very low because of intense erosion in these environments. Although few landslides are dated, many failed during glacial periods when sea levels were much lower and continental shelves more exposed, so sediments laid down are now below sea level and probably eroded during post-glacial marine transgression. The best studied passive margins area those of the North Atlantic along the coasts of Europe and North America. Here the large number of focussed international initiatives, and the high scientific interest from surrounding nations, have resulted in an extensive database of submarine landslides, their depositional character, age and triggering mechanisms.

From these studies, it is apparent that there is a strong climate control on submarine landslides, which is both geographical and temporal. In the Atlantic, continental margins may be defined by latitudinal variations that may geographically be classified as 'glaciated' north of $56^{\circ} \mathrm{N}$ (southern tip of Norway), 'glacially-influenced' between $26^{\circ} \mathrm{N}$ to $56^{\circ} \mathrm{N}$, and non-glaciated south of $26^{\circ} \mathrm{N}$ (Figure 3). In these areas, the only major tsunamis recorded are from the prehistoric landslide event of Storegga off Norway dated at 8,200 years BP and Grand Banks, 1929 off Canada. Both of these are located in the 'glaciated' regions and reflect the strong temporal climate control from the changing sedimentation regimes during the glacial and interglacial periods operating over the past 400,000 years. Although there is a general recognition of the climate control on submarine landsliding the relationships are complex, and as yet have to be established in detail, especially landslide triggering. The main constraint is the age dating of the landslides. Whereas there is now high-resolution age dating of climate change over the late Quaternary and Holocene, few landslides, especially in the Atlantic are dated to the same resolution. Thus relationships remain uncertain.

When the PNG tsunami struck, a major investigation into the Storegga landslide was just beginning after the discovery of the Ormen Lange gas field located beneath the excavated slide area. The motivation for the Storegga research was because of the potential hazard of further landsliding triggered by gas extraction. There was concern that this extraction might generate another hazardous submarine landslide and tsunami similar to that of $8,200 \mathrm{BP}$. Evidence from sediments deposited from the tsunami on the coasts of Norway, The Faroe Islands, The Shetlands and Scotland, reached elevations of up to $20 \mathrm{~m}$ or more. As with PNG, the hydroacoustic data showed that the Storegga landslide failure mechanism was different to theoretical models. It was a deforming, translational landslide (not a slump) which, rather than failing from the top down, was retrogressive, and failed from the bottom at water depths of $1000 \mathrm{~m}$. It was probably triggered by an earthquake resulting from crustal unloading during the deglaciation of Fennoscandia. 
The research showed that there were a number of landslides at the location of Storegga which took place at the end of each 120,000 year interglacial cycle associated with the waxing and waning of the ice sheets and their associated changes in sea level. The 8,200 year old landslide released a massive $2,400 \mathrm{~km}^{3}$ of sediment into the ocean, one of the largest landslides on Earth. Destabilisation prior to failure was related to rapid sediment loading from glacial deposits, which generated excess pore pressure and reduced the effective shear strength of the underlying interglacial clays deposited from contour currents. This association led to the failure from the base in a retrogressive manner. The climatic controls on sedimentation preconditioned the sediment mass, which was subsequently triggered by earthquake shock (Figure 9). The tsunami generated by the landslide was $10 \mathrm{~m}$ on the coast of Norway but over $20 \mathrm{~m}$ along the coasts of Scotland and the Shetland islands.

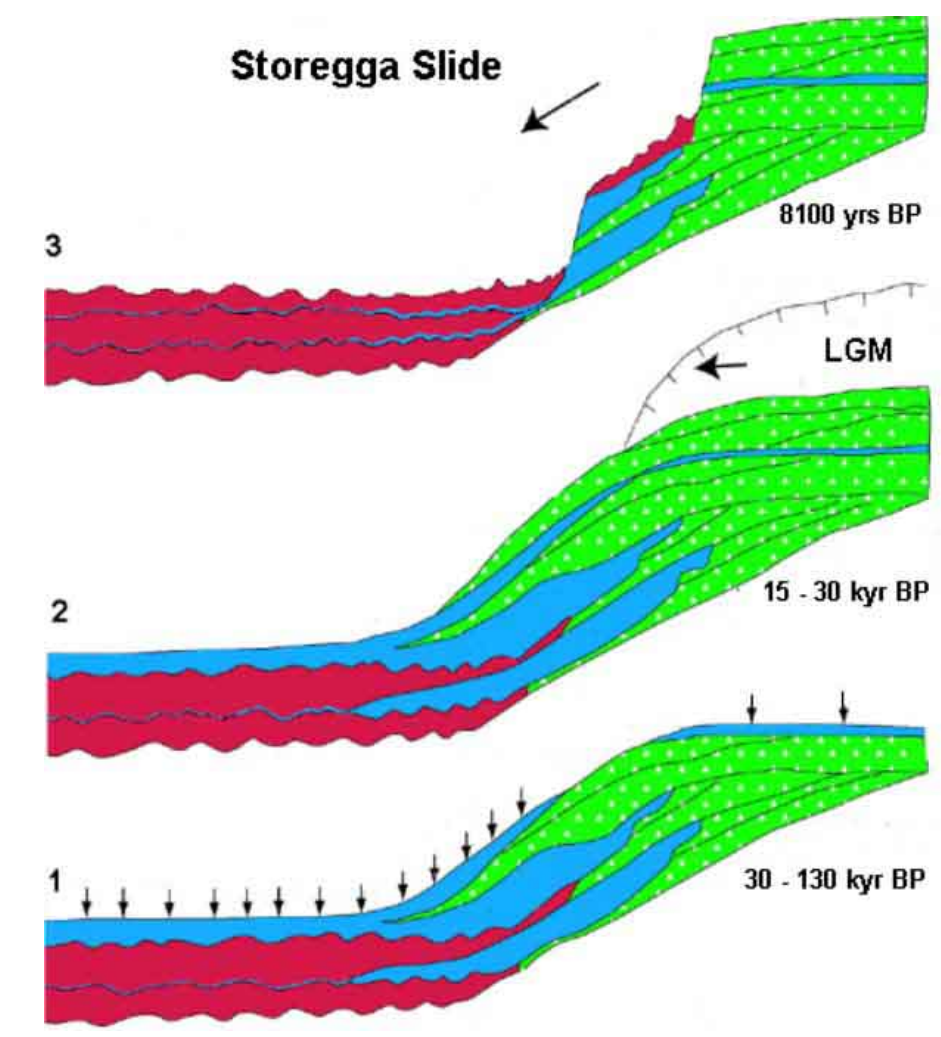

Figure 9 The cyclic deposition and slide processes in the Ormen Lange area of the Storegga slide. Green, glacial sediments; red, slide deposits; blue, marine sediments. (1) Last interglacial with deposition of soft marine clays. (2) Last glacial maximum (LGM) with the ice at the shelf edge and deposition of glacial sediments. (3) The Storegga Slide. The figure shows two older slide scars that are filled with marine clays. (Reproduced from Bryn et al., 2005)

The Grand Banks tsunami (Figure 3) of 1929 killed 27 people. Early research on the event predates modern MBES seabed mapping technologies and earthquake recording. For example, there is still little MBES data over the area of the landslide. Both the earthquake and tsunami mechanism have been subject to considerable controversy. Even now, careful reading of the published papers is required to determine the sequence of events, which are complicated. Much of the evidence on the tsunami mechanism is from papers published on the earthquake, which was strikeslip and, initially, identified as the tsunami source, although today its $M w 7$ magnitude would have caused this to be discounted. The submarine telephone cable breaks were at first attributed to the earthquake rupture extending to the seabed. Some breaks were instantaneous, and due to the earthquake, but some were sequential. It was not until 1950 that the sequential cable breaks were first proposed as the result of downslope sediment movement. In 1995, a re-evaluation of the earthquake mechanism demonstrated that this could not have generated the tsunami. The first numerical model of the tsunami was published as late as 2005 confirming the landslide mechanism, which is broadly similar to that of Storegga, retrogressive and translational. The sediment failure covered an area of $200,000 \mathrm{~km}^{2}$ with the $200 \mathrm{~km}^{3}$ of sediment transported deposited over an area of $150,000 \mathrm{~km}^{2}$. The initial sediment failure was not large, but triggered numerous retrogressive thin failures that overlapped.

\section{Convergent margins}

PNG is the best known and researched submarine landslide tsunami along a convergent margin. Other convergent margin landslide tsunamis include those of Messina (1908), Makran (1945) Aleutians (1946), Alaska (1964) Puerto Rico (1918), Flores Islands (1992) and Java (2006) (Figure 3). 600 people died in the Java tsunami and 1,000 at Flores, where the highly focussed tsunami flooded up to $25 \mathrm{~m}$ above sea level. Although suspected, for most of these events the submarine landslide contribution remains uncertain, because there are no marine surveys to evaluate the seabed for landslides that can be used to underpin numerical tsunami models. Hydroacoustic data has been used to re-evaluate the Aleutians, Alaska, Messina, Puerto Rico and the Aleutians.

The great Alaska earthquake of 1964 directly generated a tsunami, but also triggered sediment failures in fjords along the nearby coast which also generated local tsunamis (Figure 3). At Seward a one kilometre section of the waterfront collapsed into the sea, creating a $10 \mathrm{~m}$ high tsunami. The destruction was compounded by the earthquake-generated tsunami, also $10 \mathrm{~m}$ high, arriving 30 minutes later. Most of the 13 people who died were inundated by the tsunamis. At Valdez, the waterfront collapsed as the seabed failed, and generated a tsunami of up to $52 \mathrm{~m}$ in which 32 people died.

The most devastating convergent margin tsunami (Messina) after PNG was in 1908, in the lonian Sea (Figure 3). 50,000 people died in the earthquake from collapsed buildings in Messina and Calabria, but approximately 10,000 drowned in the ensuing tsunami. The earthquake magnitude $\left(M_{s}=7.1\right)$ located in the Messina Strait is incompatible with both the height and extent of local tsunami runup' which extended southward along the east coast of Sicily. There were seabed cable breaks in the southern lonian Sea, so the most likely mechanism for most of the tsunami is a submarine landslide off the east coast of Sicily. Although there have been numerous attempts to identify its location, so far there has been no success. The local tsunami from the Aleutians, 1946 earthquake is now generally agreed to be have been the result of a submarine landslide. There is still controversy over the tsunami from the Puerto Rico earthquake of 1918 , with the landslide contribution still disputed.

The most recent devastating tsunami, which again has proved seminal, was on March $11^{\text {th }} 2011$, on the east coast of Honshu Island, Japan. Yet again, the mechanism has proved to be controversial. In the context of the $M w 9$ earthquake, which at first was considered to be the only 
tsunami mechanism, no other additional cause might have reasonably been considered likely. However, the elevated (40 m) and focussed runups along the Sanriku coast of northern Honshu Island were north of the main earthquake rupture. These runups could not be reproduced by numerical modelling of the tsunami only from the earthquake. Thus, the elevated tsunami elevations suggested an additional mechanism, with this most likely being a landslide located offshore. Fortunately, off the east coast of Japan, there is a comprehensive data set of multibeam bathymetry from before and after the earthquake (Figure 10). Based on these data sets, together with seismic data, major seabed movement of $\sim 100 \mathrm{~m}$ was identified and attributed to an earthquake-triggered slump. Numerical modelling of a dual, earthquake and submarine landslide, mechanism (Figure 11) best reproduces the tsunami elevations recorded along the north Honshu coast (Figure 12).

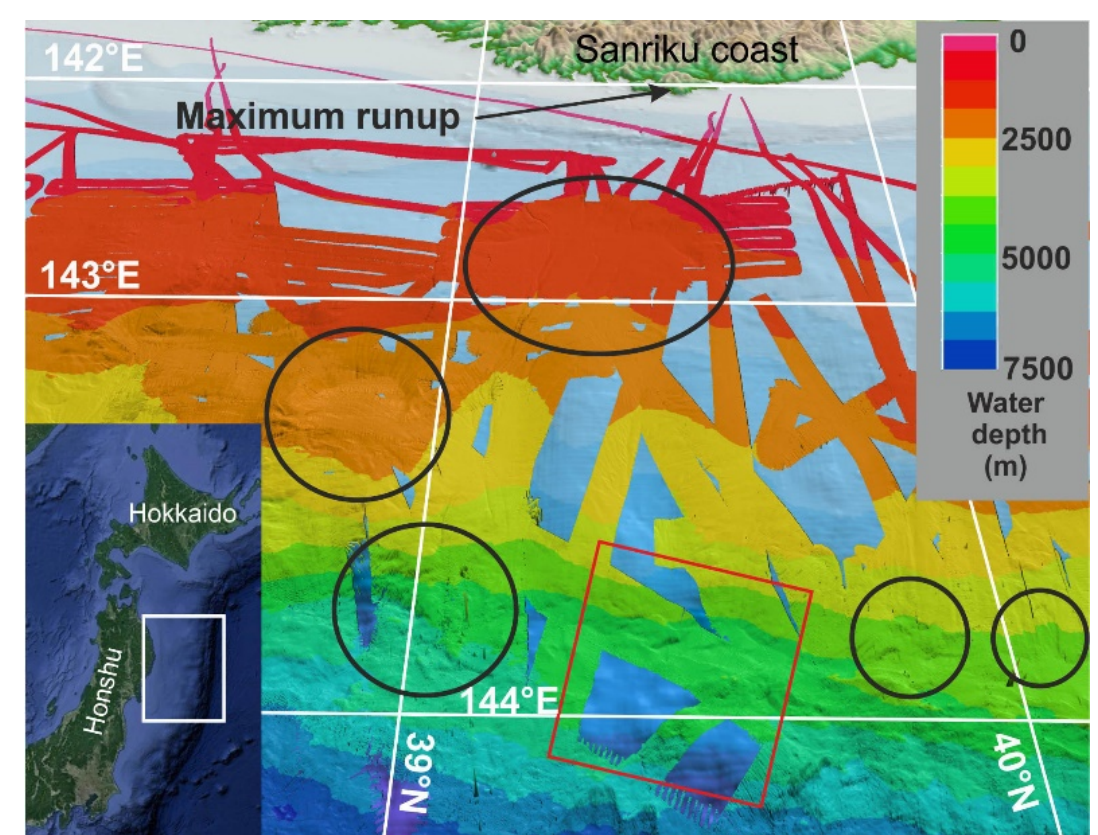

Figure 10 Multibeam bathymetry off the east coast of Japan, showing submarine landslides (SLs). Black ellipses/circle are SLs: Red square is the location of the SMF triggered by the March 2011 earthquake. (Reproduced from Tappin et al. 2014).

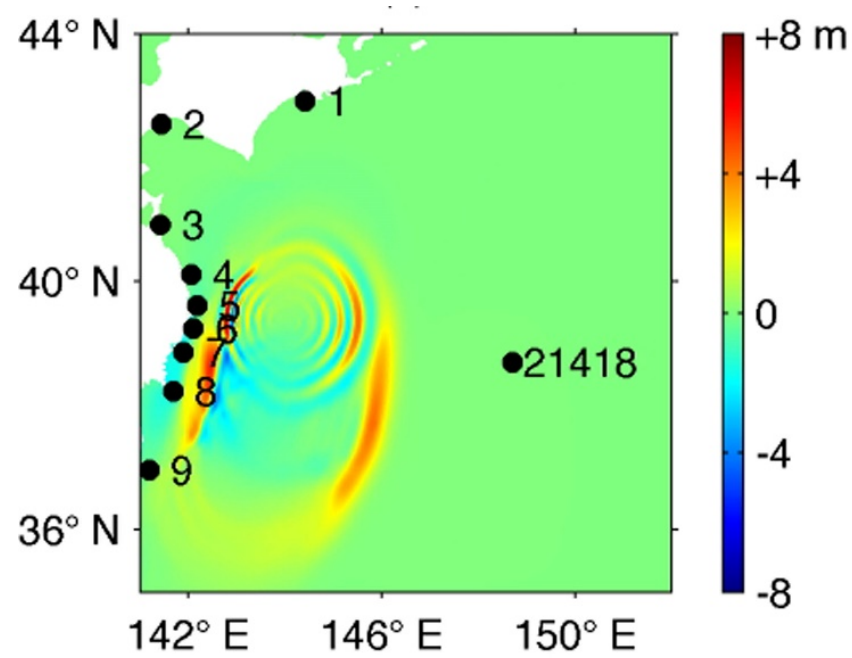

Figure 11 Comparison of tsunami wave surface elevations from the earthquake and submarine landslide generated 15 min after the Japan, 2011 earthquake. The earthquake tsunami (to the south) is almost linear compared to the circular wave train from the submarine landslide (to the north). (Reproduced from Tappin et al. (2014).

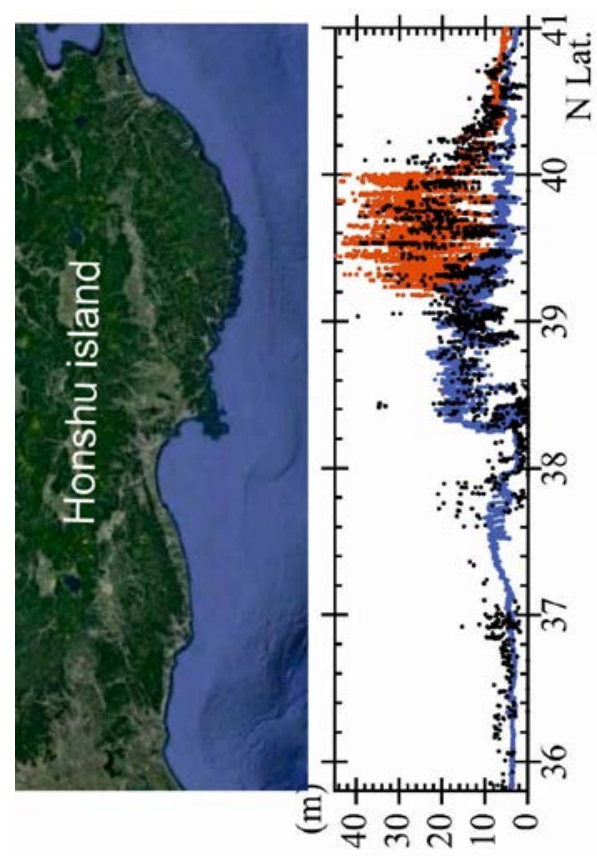

Figure 12 Tsunami coastal runup and modelled simulations from the Japan 2011 tsunami. Black dots are elevations from field surveys, blue is the simulation from the earthquake alone and red is from the dual source earthquake and submarine landslide (in part reproduced from Tappin et al. 2014) 


\section{Volcanic flank collapse}

Flank collapse of volcanoes is analogous, in terms of tsunami generation, to submarine sediment failures along passive and convergent margins. The research on flank collapse tsunamis of the Hawaiian Islands predated PNG by over 30 years (Figure 13). Although tsunami generation from collapse has been controversial, recent research on tsunami sediments on the big island of Hawaii supports the original proposal that the flank failures generate high elevation tsunamis. Because the tsunamis are prehistoric, there are no observations, so they were first identified from coarse-grained, coral-bearing sediments at elevations up to 100's metres on some of the islands (Figure 14). These sediments have alternatively been interpreted as the result of sea level high-stands, hence the controversy over the tsunami potential from the flank collapses.

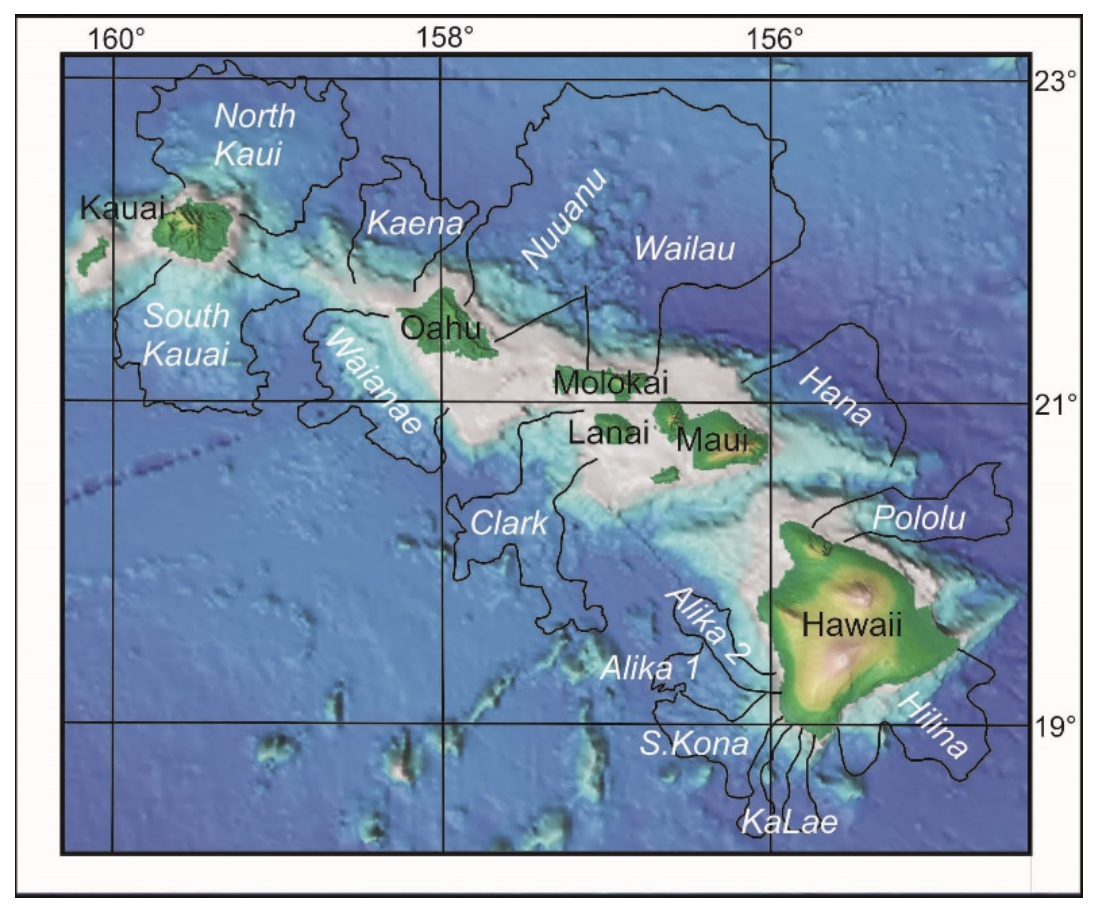

Figure 13 Seabed morphology from the Hawaiian Islands showing locations and extents of the giant submarine landslides. (Reproduced from Tappin, 2010

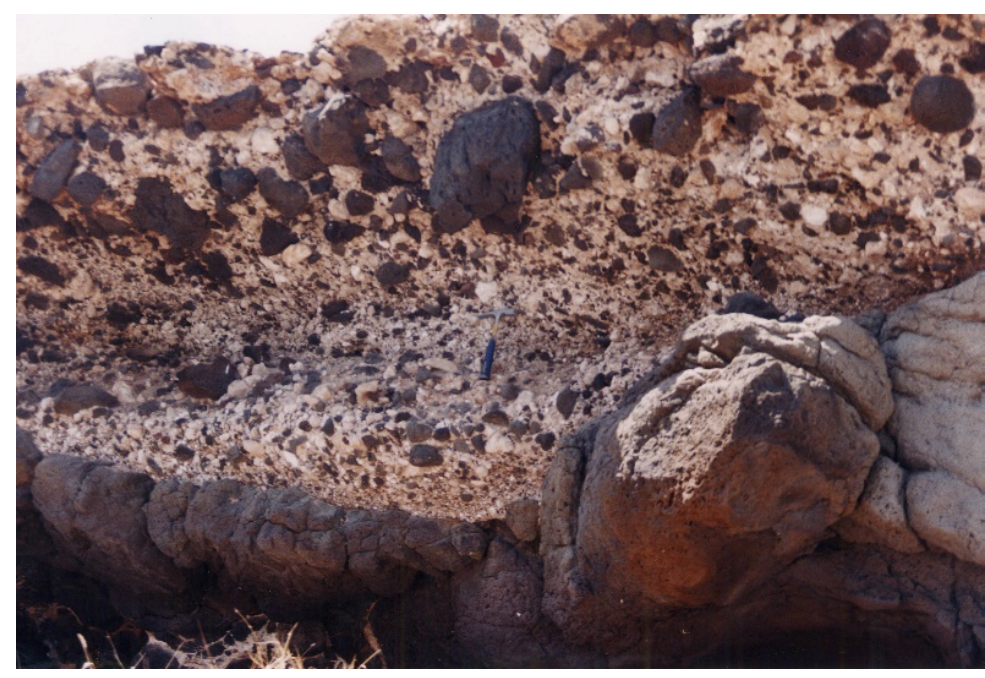

Figure 14 Coarse coralliferous gravels on Lanai in (see Fig. 13) the Hawaiian Islands deposited from the tsunamis generated from the volcanic flank collapses (Photograph by D R Tappin).

At the root of the controversy over the interpretation of the sediments has been the elevation of the islands when the sediments were laid down. The flank collapses (and sediments) are thousands to hundreds of thousands years old. Since they happened the elevations of most Hawaiian Islands have changed. Research on the big island of Hawaii shows that it has been subsiding for hundreds of thousands of years. Thus, from dating the sediments preserved here and from their present elevation, their original elevation at time of deposition can be established. In the north of the island, coralliferous gravels are found at sea level and have been dated at 120,000 years BP, the same age as the Alika 2 landslide just offshore (Figure 13) which has been proposed as generating the tsunami from which they were deposited. Over the 120,000 year interval Hawaii has been subsiding at a rate of $3.4 \mathrm{~mm}$ per year. Hence when they were deposited their elevation was at 340 metres above present sea level. Numerical models of a tsunami generated by the Alika 2 landslide, developed from the PNG tsunami, suggest that large-volume flank collapses can generate local tsunamis hundreds of metres in elevation (Figure 15). The sediments found on Hawaii thus validate the numerical modelling of the tsunami from Alika 2. Age dating of the Hawaiian landslides shows they are probably controlled by changes in climate at the turnover from cold, glacial conditions and warmer interglacials. 


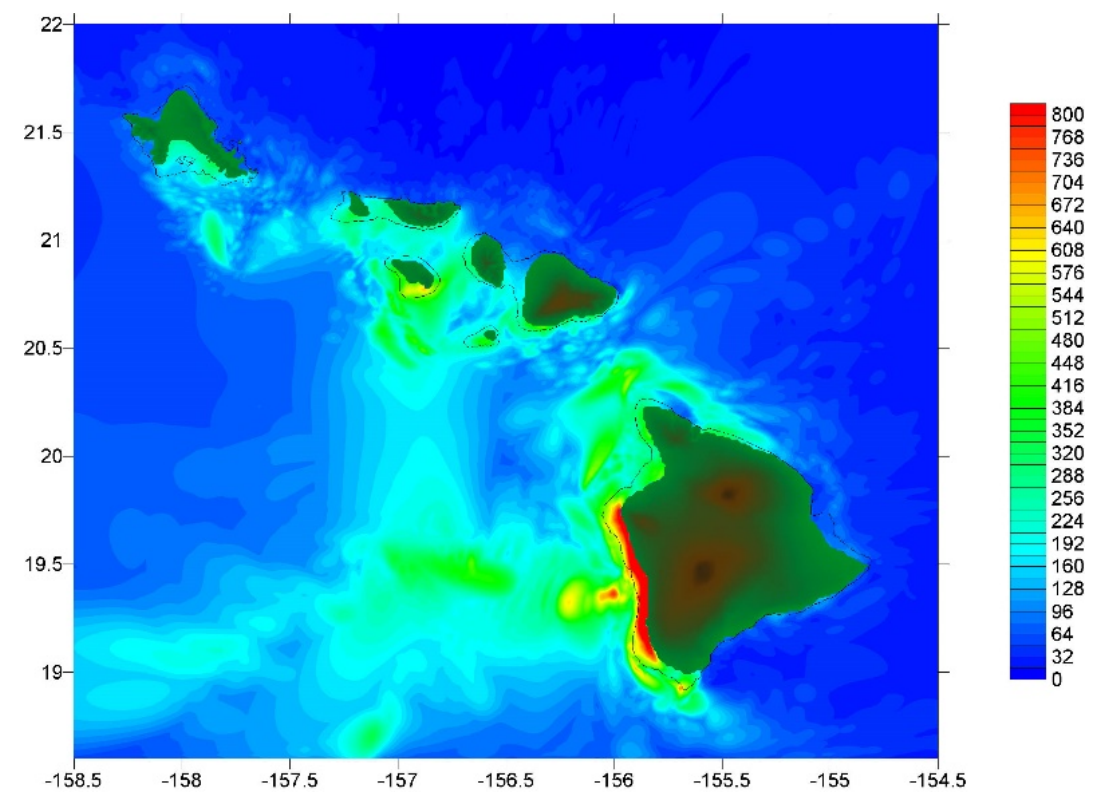

Figure 15 Maximum wave heights of the tsunami generated from the Alika 2 landslide (see Figure 10). (Reproduced from McMurtry et al. 2003).

Tsunami generation from flank collapses in the Canary Islands has also been controversial, especially in respect to their impact in the far field. Notwithstanding, locally, as evidenced again by onland boulder deposits, the tsunamis measure 100's of metres in elevation and would be devastating if they occurred. In the Canary Islands, however, the driving mechanisms of volcanic collapse are probably tectonic or eruption generated, not climatic.

The debates over the tsunamis generated in the Hawaiian and Canary are put somewhat into a perspective by actual historical examples from Japan. Collapse on Komagatake volcano, Hokkaido, in 1640, resulted in a large-scale debris avalanche that flowed into the sea, causing a tsunami in which more than 700 people died. Also in Hokkaido in 1741, volcanic collapse on Oshima-Oshima Island created a tsunami and approximately 2,000 fatalities. The catastrophic collapse was both submarine and subaerial. The tsunami generated local runups of up to $13 \mathrm{~m}$. In the far-field, over 1,000 km to the southwest, there were runups of 3-4 m on the coast of Korea. In 1792, collapse on Mt Unzen led to Japan's worst historical volcanic disaster. A debris avalanche, triggered by an earthquake, swept through Shimabara City and into the Ariaka Sea. Approximately 15,000 peopled ided, 10,000 of which were from the tsunami. The most recent tsunami caused by a volcanic flank failure was in 2002, on Stromboli, in the Aeolian Islands. The local tsunami was up to $10 \mathrm{~m}$ above sea level and caused significant damage to buildings on the eastern coast of the island but no loss of life. The cause of the tsunami was a lateral collapse comprised probably of two failures, the first submarine the second subaerial.

\section{Submarine landslide tsunami - the hazard remains undefined}

Since the1998, PNG event the tsunami hazard from submarine landslides has been more widely recognised, with PNG transformative in this major advance. The main controls on tsunami generation from submarine landslides include, the initial acceleration (cf. earthquakes), volume and water depth. The type of submarine failure - slumps or translational slide - is also an important control. Slumps per unit volume have the potential to generate larger tsunamis than translational slides.

Extensive mapping of continental margins now shows that submarine landslides are commonly present (Figure 3). Along passive margins there is a strong climate control on sediment failure. Research in the Atlantic suggests that failure is related to sedimentation regimes controlled in part by the 120,000-year interglacial/glacial cycles, with triggering mainly from earthquakes. The dominant controls on landslides along convergent margins are not as well established, but more likely to be dominated by local sedimentation regimes, with triggering from earthquakes. Earthquake shaking is also shown to both weaken and strengthen sediment.

Only four major submarine landslide tsunamis have been identified, researched and validated, Storegga, Grand Banks, Papua New Guinea and Japan. Two of these, PNG and Japan, resulted in significant loss of life. Other events such as Messina (1908), Makran (1945) Aleutians (1946), Alaska (1964) Puerto Rico (1918), Flores Islands (1992) and Java (2006), confirm the potential hazard but still require further research to understand the specific mechanisms. It is likely that as more areas are investigated with hydroacoustic technology, more landslide tsunamis will be identified.

There is a significant tsunami hazard from volcanic collapse. From research in Hawaii, major flank collapse can generate high elevation tsunamis, with the collapses again climate controlled. In the Canary Islands, the collapses are tectonic or eruption related. In both locations there is a major local hazard, but the hazard in the far field is uncertain, but probably related to the collapse volume.

It is likely that many of the landslides now mapped (Figure 3) generated tsunamis, and it is the evidence for these events that is absent because most are prehistoric and the evidence from preserved tsunami deposits is lacking. Large areas of seabed remain unmapped, and as these are explored and our understanding of the extent and size of submarine landslides increases, the tsunami hazard to coastal communities will improve.

\section{Acknowledgments}

This paper is published with the permission of the CEO of the British Geological Survey, NERC. 


\section{Suggestions for further reading}

Abadie, S.M., Harris, J.C., Grilli, S.T., Fabre, R., 2012. Numerical modeling of tsunami waves generated by the flank collapse of the Cumbre Vieja Volcano (La Palma, Canary Islands): Tsunami source and near field effects. J. Geophys. Res. 117, C05030.

Bondevik, S., Løvholt, F., Harbitz, C., Mangerud, J., Dawson, A., Svendsen, J.I., 2005. The Storegga Slide tsunami-comparing field observations with numerical simulations. Marine and Petroleum Geology 22, 195-208.

Bryn, P., Berg, K., Forsberg, C.F., Solheim, A., Lien, R., 2005. Explaining the Storegga Slide. Marine and Petroleum Geology 22, 11-19.

Dawson, A.G., Long, D., Smith, D.E., 1988. The Storegga Slides: evidence from eastern Scotland for a possible tsunami. Marine Geology 82, 271276.

Harbitz, C.B., 1992. Model simulation of tsunamis generated by the Storegga Slides. Marine Geology 105, 1-21.

Heezen, B.C., Drake, C.L., 1964. Grand Banks slump. AAPG Bulletin 48, 221-225.

McMurtry, G.M., Fryer, G.J., Tappin, D.R., Wilkinson, I.P., Williams, M., Fietzk, J., Garbe-Schoenberg, D., Watts, P., 2004. Megatsunami deposits on Kohala volcano, Hawaii, from flank collapse of Mauna Loa. . Geology 32, 741-744.

McMurtry, G.M., Watts, P., Fryer, G.J., Smith, J.R., Imamura, F., 2003. Giant landslides, mega-tsunamis, and paleo-sea level in the Hawaiian Islands. Marine Geology 203, 219-233.

Piper, D.J.W., Cochonat, P., Morrison, M.L., 1999. The sequence of events around the epicentre of the 1929 Grand Banks earthquake; initiation of debris flows and turbidity current inferred from sidescan sonar. Sedimentology 46(1), 79-97.

Synolakis, C.E., Bardet, J.P., Borrero, J.C., Davies, H.L., Okal, E.A., Silver, E.A., Sweet, S., Tappin, D.R., 2002. The slump origin of the 1998 Papua New Guinea tsunami. Proc. Royal. Soc., London 458(2020), 763-790.

Talling, P.J., M. Clare, M. Urlaub, E. Pope, Hunt, J.E., Watt, S.F.L., 2014. Large submarine landslides on continental slopes: Geohazards, methane release, and climate change. Oceanography 27, 32-45.

Tappin, D.R., 2013. Submarine Mass Failures as tsunami sources - their climate control, in: McGuire, W.J., Maslin, M. (Eds.), Climate Forcing of Geological Hazards. John Wiley \& Sons, Ltd, London, pp. 166-192.

Tappin, D.R., Grilli, S.T., Harris, J.C., Geller, R.J., Masterlark, T., Kirby, J.T., Shi, F., Ma, G., Thingbaijam, K.K.S., Mai, P.M., 2014. Did a submarine landslide contribute to the 2011 Tohoku tsunami? Marine Geology 357, 344-361.

Tappin, D.R., McNeil, L., Henstock, T., Mosher, D., 2007. Mass wasting processes - offshore Sumatra, in: Lykousis, V., Sakellarious, D., Locat, J. (Eds.), Submarine Mass Movements and Their Consequences. Springer, pp. 327-336.

Tappin, D.R., Watts, P., Grilli, S.T., 2008. The Papua New Guinea tsunami of 17 July 1998: anatomy of a catastrophic event. Nat. Hazards Earth Syst. Sci. 8, 243-266.

Tappin, D.R., Watts, P., McMurtry, G.M., Lafoy, Y., Matsumoto, T., 2001. The Sissano Papua New Guinea tsunami of July 1998 - offshore evidence on the source mechanism. Marine Geology 175, 1-23.

ten Brink, U.S., Andrews, B.D., Miller, N.C., 2016. Seismicity and sedimentation rate effects on submarine slope stability. Geology.

Ward, S.N., Day, S., 2001. Cumbre Vieja volcano - Potential collapse and tsunami at La Palma, Canary Islands. Geophysical Research Letters 28(17), 3397-3400.

\section{Figures}

Figure 1. Aerial photograph of the Sissano lagoon that was devastated by the PNG tsunami of July 1998 (Image courtesy of the University of Southern California tsunami website).

Figure 2. Marine geophysical mapping techniques. Using multibeam echosounder, backscatter and seismic technology the seabed and subseabed structure can be mapped to a high resolution that allows features such as landslides to be identified (From James et al, 2011. The MALSF synthesis study in the central and eastern English Channel. British Geological Survey Open Report OR/11/01).

Figure 3. Global distribution of mapped submarine landslides (SLS). Green lines: SLs on passive margins. Yellow lines: SLs located along convergent margins. Orange lines: SLs along strike-slip margins. Red lines: locations of SL generated tsunamis, or where there may be a SL contribution. Black latitudinal lines mark the boundaries of glacial and non-glacial SL influence.

Figure 4. How submarine landslides generate tsunamis. (a) Prefailure, (b) initial slip and surface drag down above the rear of the SMF, (c) positive and negative wave generation, and (d) continued wave propagation.

Figure 5.Digital elevation model of sea-floor relief with bathymetric contours offshore of northern Papua New Guinea looking south (vertical exaggeration $\mathrm{x4}$ ). The box shows the slump location in Figure 4. The red star is the associated earthquake. (Reproduced from Tappin, 2010).

Figure 6. 3-D cutaway section of the Papua New Guinea slump showing seabed bathymetry and sub-seabed seismic viewed from the northeast. (Vertical exaggeration x3). (Reproduced from Tappin, et al. 2008).

Figure 7. Seabed photographs in the area of the Papua New Guinea slump showing the seabed features that identify the recent seabed movement (D, E, F, G, H, I and J). The slump is outlined in white, labelled 'mound'. White scale bar on each photograph is approximately one metre. (Reproduced from Tappin et al., 2001).

Figure 8. Papua New Guinea tsunami; upper; time-lapse image of the maximum wave elevation in metres. Depth contours are in $500 \mathrm{~m}$ intervals. Lower. Simulated wave maxima (line) agree well with maximum water elevations (diamonds) measured onshore. (Reproduced from Tappin et al., 2001).

Figure 9. The cyclic deposition and slide processes in the Ormen Lange area of the Storegga slide. Green, glacial sediments; red, slide deposits; blue, marine sediments. (1) Last interglacial with deposition of soft marine clays. (2) Last glacial maximum (LGM) with the ice at the shelf edge and deposition of glacial sediments. (3) The Storegga Slide. The figure shows two older slide scars that are filled with marine clays. (Reproduced from Bryn et al., 2005) 
Figure 10. Multibeam bathymetry off the east coast of Japan, showing submarine landslides (SLs). Black ellipses/circle are SLs: Red square is the location of the SMF triggered by the March 2011 earthquake. (Reproduced from Tappin et al. 2014).

Figure 11. Comparison of tsunami wave surface elevations from the earthquake and submarine landslide generated 15 min after the Japan, 2011 earthquake. The earthquake tsunami (to the south) is almost linear compared to the circular wave train from the submarine landslide (to the north). (Reproduced from Tappin et al. 2014).

Figure 12. Tsunami coastal runup and modelled simulations from the Japan 2011 tsunami. Black dots are elevations from field surveys, blue is the simulation from the earthquake alone and red is from the dual source earthquake and submarine landslide (Reproduced in part from Tappin et al. 2014).

Figure 13. Seabed morphology from the Hawaiian Islands showing locations and extents of the giant submarine landslides. (Reproduced from Tappin, 2010).

Figure 14. Coarse coralliferous gravels on Lanai in (see Fig. 13) the Hawaiian Islands deposited from the tsunamis generated from the volcanic flank collapses (Photograph by D R Tappin).

Figure 15. Maximum wave heights of the tsunami generated from the Alika 2 landslide (see Figure 10). (Reproduced from McMurtry et al., 2003). 